\title{
Efeito dos níveis de concentrado sobre as características de carcaça de ovinos Morada Nova em confinamento ${ }^{1}$
}

\section{Geovergue Rodrigues de Medeiros ${ }^{2}$, Francisco Fernando Ramos de Carvalho ${ }^{3}$, Ângela Maria Vieira Batista ${ }^{3}$, Wilson Moreira Dutra Júnior ${ }^{3}$, Gladston Rafael de Arruda Santos ${ }^{4}$, Dulciene Karla Bezerra de Andrade ${ }^{5}$}

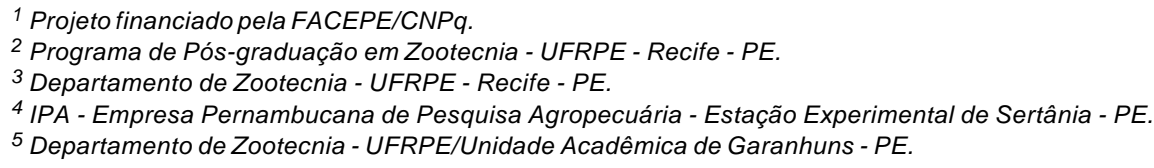

RESUMO - Avaliaram-se as características de carcaça e os rendimentos dos cortes medidos in vivo e na carcaça de ovinos Morada Nova terminados em confinamento com dietas contendo diversos níveis de concentrado. Utilizaram-se 32 cordeiros castrados, Morada Nova, com 8,11 $\pm 1,15$ meses de idade e peso inicial de 19,67 $\pm 2,97 \mathrm{~kg}$, em delineamento de blocos casualizados, cada um com oito repetições. Os animais foram abatidos com 30,0 kg e alimentados com quatro níveis de concentrado $(20,40,60$ ou $80 \%)$. Houve efeito linear crescente do nível de concentrado da dieta sobre o peso do corpo vazio e peso e o rendimento da carcaça fria e efeito linear decrescente sobre o conteúdo do trato digestório e o número de dias em confinamento. Os níveis de concentrado tiveram efeito linear crescente sobre o peso e rendimento de pescoço e efeito linear decrescente sobre os rendimentos da paleta e perna, ao passo que o peso do costilhar foi influenciado de forma quadrática pelos tratamentos. Nas medidas in vivo, apenas o perímetro da perna sofreu efeito decrescente. Nas medidas na carcaça, houve efeito linear crescente sobre a largura do tórax e a compacidade, que aumentaram com o nível de concentrado na dieta, enquanto a largura da garupa teve efeito quadrático. O uso de concentrado na dieta eleva os pesos e os rendimentos de carcaça fria, mas não aumenta os pesos e rendimentos dos cortes da carcaça de cordeiros Morada Nova.

Palavras-chave: conformação, cortes comerciais, dietas, medidas lineares, rendimentos

\section{Effect of concentrate levels on carcass characteristics of the Morada Nova breed sheep in feedlot}

\begin{abstract}
The in vivo carcass characteristics and the cut yields measured in the carcass of Morada Nova sheep finished in feedlot system fed increasing levels of dietary concentrate were evaluated. Thirty-two castrated Morada Nova lambs with $8.11 \pm 1.15$ months of age and $19.67 \pm 2.97 \mathrm{~kg}$ of initial body weight were used in this trial. The experimet was analyzed as a completely randomized block design with eight replicates per treatment. Animals were slaughtered at $30.0 \mathrm{~kg} \mathrm{BW}$ and fed diets with four concentrate levels: 20, 40, 60 or $80 \%$. Linear increasing effect of dietary concentrate on empty body weight and cold carcass weight and yield and linear decreasing effect on digestive tract content and feedlot period were observed. The neck weight and yield linearly increased and the percentage of shoulder and leg linearly decreased with the concentrate levels, while the rib weight showed quadratic effect. In the in vivo measurements, only leg perimeter presented significant effect. There was a linear increasing effect for thoracic width and carcass compactness, while the hind width showed quadratic effect. The use of concentrate in the diet increased the weight and yields of cold carcass; however this maximization did not increase the weights and yields of commercial cuts from Morada Nova lambs.
\end{abstract}

Key Words: conformation, diets, linear measurements, trading cuts, yields

\section{Introdução}

O confinamento de ovinos tem despertado o interesse de criadores na intensificação dos sistemas de produção visando diminuir as perdas de animais jovens por deficiências nutricionais e infestações parasitárias, manter a regularidade da oferta de carne e peles durante o ano e obter retorno mais rápido do capital investido, por meio

Este artigo foi recebido em 4/6/2007 e aprovado em 22/8/2008.

Correspondências devem ser enviadas para: geovergue@uol.com.br

* Endereço atual: Instituto Nacional do Semi-Árido (INSA). 
da redução da idade ao abate, da pressão de pastejo na caatinga e da produção de carcaças com qualidade superior à de carcaças obtidas em condições de pastejo.

É consenso na literatura sobre a existência de fatores determinantes das características qualiquantitativas da carcaça, como genótipo, sexo, idade, peso ao abate, sistema de produção e nutrição (Snowder et al., 1994; Sañudo, 2002; Lawrie, 2005). O genótipo do animal constitui importante fator no sistema de produção de carne em regime intensivo de criação, pois influencia a precocidade, a velocidade de ganho de peso e a eficiência alimentar, características diretamente relacionadas à redução dos custos de alimentação e que têm efeitos diretos sobre o peso e a deposição de músculos e gordura na carcaça (Purchas et al., 2002; Näsholm, 2004).

Segundo Traldi (1990), as raças deslanadas do Nordeste podem resultar em cordeiros precoces para utilização em cruzamentos industriais, como os ovinos Santa Inês para abate aos 180 dias com peso de $25,5 \mathrm{~kg}$ e que podem ter rendimento de $46 \%$ de carcaça quente. Figueiredo et al. (1982) verificaram que animais das raças Morada Nova e Somalis atingiram peso de abate $(23,25$ e 22,86 kg) aos 285,40 e 294,05 dias com carcaças pesando 11,084 e 10,86 kg, respectivamente.

Em sistemas de confinamento, é imprescindível a manutenção dos animais com dietas que atendam às exigências nutricionais para obtenção do desempenho desejado, de forma que a relação custo/benefício seja lucrativa para o produtor e possa proporcionar carcaças com qualidade e aceitação no mercado. Conforme descrito por Susin (2001), a dieta de custo mínimo em confinamentos é aquela com alta porporção de concentrado.

Gonzaga Neto et al. (2006) reportam que o aumento na quantidade de concentrado, de 30 para $60 \%$, na dieta de cordeiros Morada Nova elevou os rendimentos de carcaça quente e fria, assim como o rendimento biológico. Alves et al. (2003) também verificaram aumento no peso e rendimento de carcaça fria e no peso de corpo vazio com o aumento do nível de energia em ovinos Santa Inês. Com a mesma raça, Furusho-Garcia et al. (2001) encontraram valores de 17,33 kg; 49,66 e $47,56 \%$ para peso da carcaça fria e os rendimentos verdadeiro e comercial da carcaça, respectivamente, quando utilizaram dietas com $80 \%$ de concentrado (2,8 Mcal $\mathrm{EM} / \mathrm{kg} \mathrm{MS}$ ).

Este trabalho foi realizado com o objetivo de avaliar as características, os rendimentos dos cortes e a morfologia in vivo e da carcaça de cordeiros Morada Nova mantidos em confinamento com dietas com diversos níveis de concentrado.

\section{Material e Métodos}

O trabalho foi conduzido no Setor de Ovinocaprinocultura do Departamento de Zootecnia da Universidade Federal Rural de Pernambuco, na cidade de Recife, Pernambuco, situada na microrregião fisiográfica do Litoral Mata.

Foram utilizados 32 cordeiros da raça Morada Nova, variedade vermelha, machos castrados, com 8,11 $\pm 1,15$ meses de idade e peso inicial de $19,67 \pm 2,97 \mathrm{~kg}$, confinados em baias individuais $(1,0 \times 2,8 \mathrm{~m})$ com $0,80 \mathrm{~m}$ do piso cimentado (local do cocho) e 2,0 m do piso de chão batido, providas de comedouros e bebedouros.

Inicialmente, os animais foram submetidos a um período pré-experimental de 14 dias para adaptação às dietas e instalações; pesados, identificados, tratados contra ecto e endoparasitas e vacinados contra clostridioses.

$\mathrm{O}$ fornecimento das dietas experimentais foi feito uma vez ao dia, às 7h30, na forma de ração completa, com água sempre à disposição dos animais. Nos dias anteriores às pesagens do período experimental, os comedouros foram esvaziados, às $17 \mathrm{~h}$, para jejum dos animais. As pesagens foram realizadas a cada sete dias, com jejum prévio de sólidos de aproximadamente 14 h, do início do experimento até o abate, além de algumas pesagens extras dos animais com peso corporal próximo ao peso de abate.

Ao atingirem aproximadamente $32 \mathrm{~kg}$ de peso vivo, os animais foram pesados para obtenção do peso pré-abate (PPA) e submetidos a jejum de sólidos por 16 horas. Decorrido esse tempo, os animais foram novamente pesados para obtenção do peso ao abate (PA) e determinação da perda de peso decorrente do jejum (PJ), que foi calculada pela fórmula: PJ, $\%=(P P A-P A) \times 100 / P V$.

As dietas experimentais continham 15,91 a 18,35\% de PB e foram formuladas com feno moído de capim-tifton 85 (Cynodon dactylon) e quatro níveis de concentrado (20, 40, 60 e $80 \%$ ), composto de milho moído, farelo de soja e óleo vegetal. Além desses ingredientes, utilizaram-se mistura mineral, calcário calcítico e bicarbonato de sódio (Tabela 1). A dieta com maior nível de concentrado foi formulada de acordo com o NRC (1985), para atender às exigências nutricionais de animais com $20 \mathrm{~kg}$ de PV e ganho diário de 250 g/animal.dia.

Previamente ao abate, quando os animais atingiram $30,0 \mathrm{~kg}$, determinou-se de maneira subjetiva a condição corporal, por palpação da região lombar, logo após o $13^{\circ}$ par de costelas, atribuindo-se nota de 1,0 a 5,0 segundo definições de Susin (1996). No momento do abate, os animais foram insensibilizados, por atordoamento na região 
Tabela 1 - Composição das dietas experimentais, com base na matéria seca (MS)

\begin{tabular}{|c|c|c|c|c|}
\hline \multirow[t]{2}{*}{ Ingrediente, $\%$ na MS } & \multicolumn{4}{|c|}{ Nível de concentrado, $\%$} \\
\hline & 20 & 40 & 60 & 80 \\
\hline Feno de capim-tifton & 78,90 & 60,00 & 40,0 & 20,0 \\
\hline Grão de milho moído & 0,00 & 18,50 & 36,0 & 54,0 \\
\hline Farelo de soja & 17,70 & 18,20 & 20,0 & 21,0 \\
\hline Óleo vegetal & 2,50 & 2,50 & 2,50 & 2,50 \\
\hline Bicarbonato de sódio & 0,00 & 0,00 & 0,00 & 0,50 \\
\hline Cloreto de sódio & 0,20 & 0,10 & 0,00 & 0,00 \\
\hline Calcário calcítico & 0,20 & 0,50 & 0,50 & 0,80 \\
\hline Mistura mineral ${ }^{1}$ & 0,50 & 0,20 & 1,00 & 1,20 \\
\hline \multicolumn{5}{|l|}{ Composição } \\
\hline Matéria seca, MS (\%) & 89,38 & 89,12 & 88,96 & 88,84 \\
\hline Proteína bruta, PB (\%) & 15,91 & 16,50 & 17,62 & 18,35 \\
\hline Extrato etéreo, EE (\%) & 4,14 & 4,57 & 4,96 & 5,36 \\
\hline Fibra em detergente neutro, FDN (\%) & 65,41 & 54,47 & 42,68 & 30,85 \\
\hline FDNcorrigida para proteína, $\mathrm{FDN}_{\mathrm{PB}}(\%)$ & 62,77 & 50,88 & 38,25 & 25,54 \\
\hline Fibra em detergente ácido, FDA (\%) & 34,53 & 27,56 & 20,41 & 13,20 \\
\hline Carboidratos totais, CT $(\%)$ & 71,25 & 71,49 & 70,49 & 69,60 \\
\hline Carboidratos não-fibrosos (\%) & 8,45 & 19,08 & 29,30 & 39,65 \\
\hline Matéria mineral, MM (\%) & 8,69 & 7,41 & 6,91 & 6,67 \\
\hline Nutrientes digestíveis totais, NDT (\%) & 57,89 & 64,79 & 71,31 & 77,63 \\
\hline Energia metabolizável (Mcal de EM/kg de MS) & 2,10 & 2,34 & 2,56 & 2,81 \\
\hline
\end{tabular}

atlanto-occipital seguido de sangria, por quatro minutos, pela seção da carótida e da jugular. O sangue foi recolhido em recipiente previamente tarado para posterior pesagem.

Após esfola e evisceração, foram retiradas a cabeça (secção na articulação atlanto-occipital), as patas (secção nas articulações carpo e tarsometatarsianas) e a cauda e registrados os pesos de carcaça quente (PCQ). O trato gastrointestinal (TGI) foi pesado, cheio e vazio, para determinação do peso do corpo vazio (PCVZ) e do rendimento biológico ou verdadeiro $(\mathrm{RV}, \%=\mathrm{PCQ} / \mathrm{PCVZ} \times 100)$.

As carcaças foram resfriadas por 24 horas a $\pm 4^{\circ} \mathrm{C}$ em câmara frigorífica, com as articulações tarsometatarsianas distanciadas $14 \mathrm{~cm}$, por meio de ganchos. Depois de resfriadas, as carcaças foram pesadas para obtenção do peso da carcaça fria $(\mathrm{PCF})$ e cálculo da perda por resfriamento $(\mathrm{PR}, \%=\mathrm{PCQ}-\mathrm{PCF} / \mathrm{PCQ} \times 100)$. Foram calculados os rendimentos de carcaça quente $(\mathrm{RCQ}, \%=\mathrm{PCQ} / \mathrm{PA} \times 100)$ e fria $(\mathrm{RCF}, \%=\mathrm{PCF} / \mathrm{PA} \times 100)$ e o índice de compacidade da carcaça $(\mathrm{ICC}, \mathrm{kg} / \mathrm{cm}=\mathrm{PCF} /$ comprimento interno da carcaça fria).

Antes das medidas lineares e da seção das carcaças, realizou-se avaliação subjetiva para determinação do grau de conformação, pela atribuição de notas de 1,0 a 5,0 (1,0 para a pior e 5,0 para a melhor conformação), segundo metodologia adaptada de Müller (1980) e Colomer-Rocher (1988).
As carcaças foram seccionadas ao meio e as meiascarcaças foram pesadas. Na meia-carcaça esquerda, foram mensurados o comprimento interno (distância do bordo anterior da sínfise ísquio-pubiana até o bordo anterior da primeira costela); a profundidade do tórax (distância máxima entre o esterno e o dorso da carcaça); a largura do tórax (largura máxima da carcaça no nível das costelas); o comprimento da perna (distância entre o trocânter maior do fêmur e a junção tarsometatarsiana); a circunferência da perna (perímetro da perna em sua largura máxima); e a largura da garupa (largura máxima entre os trocânteres de ambos os fêmures). Depois que as medidas internas e externas foram tomadas, as meias-carcaças direita e esquerda foram seccionadas em seis regiões anatômicas (cortes comerciais), segundo metodologia proposta pelo Centro Nacional de Pesquisa de Caprinos/Embrapa, citada por Silva Sobrinho (2001): paleta, perna, lombo, costilhar, serrote e pescoço. Foram registrados os pesos individuais de cada corte para cálculo de sua proporção em relação à média das meiascarcaças e obtenção do rendimento comercial dos cortes.

Na meia-carcaça esquerda, também foi feito um corte transversal, na secção entre a $12^{\mathrm{a}}$ e $13^{\mathrm{a}}$ costelas, para mensuração da área de olho-de-lombo (AOL) do músculo Longissimus dorsi, pelo traçado do contorno do músculo em folha plástica de transparência, para posterior determi- 
nação da área em planímetro digital, utilizando-se a média de três leituras. Ainda no Longissimus dorsi, utilizando-se paquímetro, foi medida a espessura de gordura de cobertura sobre a secção do músculo (entre a última vértebra torácica e primeira lombar) a dois terços do comprimento total da área de olho-de-lombo (Müller, 1980).

O delineamento experimental utilizado foi o de blocos casualizados, com quatro níveis de concentrado e oito repetições, de modo que os blocos foram formados de acordo com o peso inicial dos animais. Além da análise de variância, foi realizada análise de regressão considerando os níveis de concentrado na dieta. Os critérios utilizados para a escolha das equações foram o comportamento biológico, o coeficiente de determinação $\left(\mathrm{r}^{2}\right)$ e a significância para os parâmetros de regressão, obtida pelo teste "t Student”, para o nível de 5\% de probabilidade. As análises estatísticas foram realizadas com auxílio computacional do programa SAEG (UFV, 2001).

\section{Resultados e Discussão}

O peso ao jejum (PJ), o peso ao abate (PA), o peso de carcaça quente (PCQ), o rendimento de carcaça quente (RCQ), o rendimento verdadeiro (RV), a perda por resfriamento $(\mathrm{PR})$ e a perda ao jejum $(\mathrm{PJ})$ não foram influenciados $(\mathrm{P}>0,05)$ pelos níveis de concentrado na dieta, o que pode estar relacionado ao critério de peso estabelecido para o abate $( \pm 30,0 \mathrm{~kg})$ (Tabela 2$)$.

O peso ao abate, principalmente a proporção de músculos e gordura, tem sido associado à qualidade da carcaça e determinam as preferências dos consumidores e os aspectos relacionados às questões econômicas. Além disso, fatores como o potencial genético para ganho, peso à maturidade, idade e plano nutricional, devem ser considerados.

Sob o ponto de vista econômico, Siqueira et al. (2001) avaliaram animais Ile de France $\times$ Corriedale confinados e recomendaram $28 \mathrm{~kg}$ como o peso-referência para o abate. Snowder et al. (1994) relataram que os melhores pesos de abate para ovinos Targhee, Ramboullet e Polypay e Columbia variaram de 45 a $47 \mathrm{~kg}$.

Os ovinos deslanados do Nordeste brasileiro têm em geral porte e peso corporal inferiores aos das raças especializadas para carne. De acordo com Zapata et al. (2001), o peso ótimo de abate desses animais deve ser definido para cada raça, considerando as preferências do mercado consumidor. Figueiredo et al. (1982) verificaram que ovinos Santa Inês em pastagem nativa atingiram peso ao abate de $25 \mathrm{~kg}$ dos 6 aos 7 meses de idade. Ovinos Morada Nova e Somalis, por sua vez, ao serem confinados, alcançaram essa faixa de peso aos 9 meses de idade.

Os níveis de concentrado neste estudo tiveram efeito linear crescente $(\mathrm{P}<0,05)$ sobre o peso do corpo vazio (PCVZ), o peso de carcaça fria (PCF) e o rendimento de carcaça fria (RCF) e efeito linear decrescente sobre o conteúdo do trato gastrintestinal (TGI) e o número de dias em confinamento.

Quando o peso da carcaça quente é subtraído do peso do corpo vazio (PCVZ), encontram-se valores de 11,76; 12,$08 ; 12,24 ; 12,91 \mathrm{~kg}$, equivalentes a 46,81; 47,02; 47,31 e $48,14 \%$ do PCVZ. Esses valores são altos e representam os

Tabela 2 - Características de carcaça de cordeiros Morada Nova terminados em confinamento com diversos níveis de concentrado na dieta

\begin{tabular}{|c|c|c|c|c|c|c|c|}
\hline & \multicolumn{4}{|c|}{ Nível de concentrado (\%) } & \multirow[t]{2}{*}{$\mathrm{CV}(\%)$} & \multirow[t]{2}{*}{ Equação de regressão } & \multirow[t]{2}{*}{$\mathrm{r}^{2}$} \\
\hline & 20 & 40 & 60 & 80 & & & \\
\hline Peso inicial, $\mathrm{kg}$ & 20,37 & 19,42 & 19,0 & 19,92 & - & - & - \\
\hline Peso pré-abate, kg & 32,45 & 32,48 & 32,17 & 32,66 & 3,93 & $\hat{\mathrm{Y}}=32,44 \mathrm{~ns}$ & \\
\hline Peso ao abate, $\mathrm{kg}$ & 30,92 & 31,17 & 30,66 & 30,98 & 3,43 & $\hat{\mathrm{Y}}=30,93 \mathrm{~ns}$ & \\
\hline Peso do corpo vazio, kg & 25,12 & 25,69 & 25,87 & 26,82 & 5,04 & $\hat{Y}=24,5551+0,0264286^{*} C^{1}$ & 0,93 \\
\hline Conteúdo do trato digestório, $\mathrm{kg}$ & 5,80 & 5,47 & 4,80 & 4,16 & 21,96 & $\hat{Y}=6,45427-0,0279098 * C$ & 0,98 \\
\hline Dias de confinamento (dias) & 123,37 & 86,62 & 75,25 & 52,5 & 34,58 & $\hat{\mathrm{Y}}=140,437-1,1200^{*} \mathrm{C}$ & 0,96 \\
\hline Peso da carcaça quente, $\mathrm{kg}$ & 13,36 & 13,61 & 13,63 & 13,91 & 5,78 & $\hat{\mathrm{Y}}=13,62 \mathrm{~ns}$ & \\
\hline Peso da carcaça fria, $\mathrm{kg}$ & 12,94 & 13,02 & 13,33 & 13,62 & 5,24 & $\hat{Y}=12,6477+0,0116166 * C$ & 0,95 \\
\hline Rend. de carcaça quente, $\%$ & 43,24 & 43,66 & 44,52 & 44,92 & 6,02 & $\hat{\mathrm{Y}}=44,08 \mathrm{~ns}$ & \\
\hline Rend. de carcaça fria, $\%$ & 41,59 & 41,78 & 43,54 & 43,96 & 5,64 & $\hat{Y}=40,8017+0,0398916 * C$ & 0,85 \\
\hline Rendimento verdadeiro, $\%$ & 53,15 & 53,03 & 52,79 & 51,91 & 4,98 & $\hat{\mathrm{Y}}=52,72 \mathrm{~ns}$ & \\
\hline Perda por resfriamento, $\%$ & 2,90 & 3,96 & 2,09 & 1,98 & 56,38 & $\hat{\mathrm{Y}}=2,73 \mathrm{~ns}$ & \\
\hline Perda no jejum, $\%$ & 4,72 & 4,04 & 4,60 & 5,09 & 45,18 & $\hat{\mathrm{Y}}=4,61 \mathrm{~ns}$ & \\
\hline
\end{tabular}

${ }^{1}$ Nível de concentrado; * Significativo a $5 \%$ de probabilidade pelo teste $t$; ns - não-significativo. 
pesos dos componentes não-carcaça, como os órgãos, as vísceras e os subprodutos (sangue, patas, cabeça, pele e gorduras internas). Osório et al. (2002a) recomendaram que, na comercialização, visando valorizar a qualidade total do animal, deve-se considerar o "quinto quarto" (pesos dos componentes não-carcaça) e não somente a carcaça quente ou o peso vivo. $\mathrm{O}$ aumento do peso de corpo vazio $(\mathrm{P}<0,05)$ foi inversamente relacionado ao conteúdo do trato gastrintestinal. As dietas com 20 e $40 \%$ de concentrado, com maiores percentuais de fibra em detergente neutro $(65,41$ e 54,47\%; Tabela 1), e, portanto, menos digeríveis, passaram mais tempo no trato gastrointestinal durante o período de jejum, influenciando o peso vivo imediatamente anterior ao abate, fato também verificado por Mahgoub et al. (2000), Alves et al. (2003) e Haddad \& Husein (2004), que utilizaram dietas com 40 a $85 \%$ de concentrado. O conteúdo digestivo apresenta variações que dependem da natureza do alimento, da duração do jejum e do desenvolvimento do trato gastrintestinal, fatores influenciados pela idade do animal e pelo histórico nutricional (Osório et al., 2002a).

O tempo de permanência dos animais no confinamento $(123,37 ; 86,62 ; 75,25$ e 52,50 dias) decresceu linearmente $(\mathrm{P}<0,05)$ conforme aumentou a quantidade de concentrado na dieta, antecipando a idade ao abate em 70,87 dias nos animais terminados com a dietacom maiornível de concentrado. Mesmo que o ganho de peso total durante o confinamento tenha sido semelhante entre os níveis de concentrado $( \pm 11,0 \mathrm{~kg})$, deve-se considerar que menores períodos de confinamento reduzem a idade ao abate e favorecem as características de carcaça, representando menores custos de produção e proporcionando maior rotatividade de animais no confinamento/ano, amortizando mais rapidamente as despesas com instalações e alimentação, como descrito por Susin (2001), que concluiu que a dieta de custo mínimo em confinamentos é aquela com alto nível de concentrado.

Os pesos e rendimentos de carcaça fria (Figura 1) elevaram com os níveis de concentrado e de energia metabolizável na dieta, com valores de 12,94; 13,02; 13,33 e $13,62 \mathrm{~kg}$ e 41,59; 42,39; 43,54 e 43,96\%. De modo geral, a cada unidade percentual de concentrado na dieta, houve acréscimo de aproximadamente $0,02643 \mathrm{~kg}$ no peso de corpo vazio e de $0,01162 \mathrm{~kg}$ no peso de carcaça fria e redução de $0,028 \mathrm{~kg}$ no conteúdo do trato digestório e de 1,12 dias no período de confinamento.

Haddad \& Husein (2004) também observaram aumento no peso $(12,8$ e $15,7 \mathrm{~kg})$ e no rendimento de carcaça fria $(43,5$ e 48,5\%) em cordeiros Awassi alimentados com dietas contendo 40 e $80 \%$ de concentrados, respectivamente.
Segundo Ferreira et al. (1998), o nível de consumo de energia pode modificar a partição no uso da energia para a síntese de proteína ou lipídios ou no desenvolvimento de músculo e tecido adiposo. De acordo com o NRC (1985), a cada quilograma de ganho no peso de corpo vazio, há um requerimento de 1,2 Mcal de energia metabolizável para a deposição de proteína e água e de 8,0 Mcal de energia metabolizável para deposição de gordura e água. Nesse contexto, torna-se evidente a importância da quantidade de energia ofertada para o animal e da eficiência de utilização da energia metabolizável da dieta, para mantença e ganho de peso, que refletem diretamente na carcaça.

Reid et al. (1980) comentaram que a eficiência de utilização da energia metabolizável para deposição líquida de proteína e gordura é de 33 e $82 \%$, respectivamente, em ovinos com 10 a $40 \mathrm{~kg}$ de peso vivo. O NRC (1985) adotou a equação de Garret (1980) para estimar a energia líquida de mantença (ELm) e o ganho (ELg) de acordo com a energia metabolizável da dieta.

Neste trabalho, as dietas dos ovinos apresentavam valores de ELm e ELg de 1,54; 1,70; 1,83 e 1,96 Mcal e 0,95; 1,$09 ; 1,20$ e 1,31 Mcal, respectivamente. A partir desses valores, estima-se que as eficiências para mantença $(\mathrm{km})$ foram de 0,$634 ; 0,651 ; 0,663$ e 0,673; para ganho (kf), 0,391; 0,$417 ; 0,435$ e 0,450 para as dietas com 20,40,60 e $80 \%$ de concentrado. Pelo sistema AFRC (1993), as estimativas de eficiência para mantença resultaram em 0,$692 ; 0,706 ; 0,717$ e 0,729 e de kf, 0,$427 ; 0,458 ; 0,484$ e 0,51 , valores que dependem da metabolizabilidade (qm) da dieta.

Os pesos da meia-carcaça fria e do pescoço, expressos em $\mathrm{kg}$ e em $\%$, foram influenciados de forma linear crescente $(\mathrm{P}<0,05)$; os rendimentos $(\%)$ da paleta e perna, de forma linear decrescente $(\mathrm{P}<0,05)$, e o peso do costilhar,

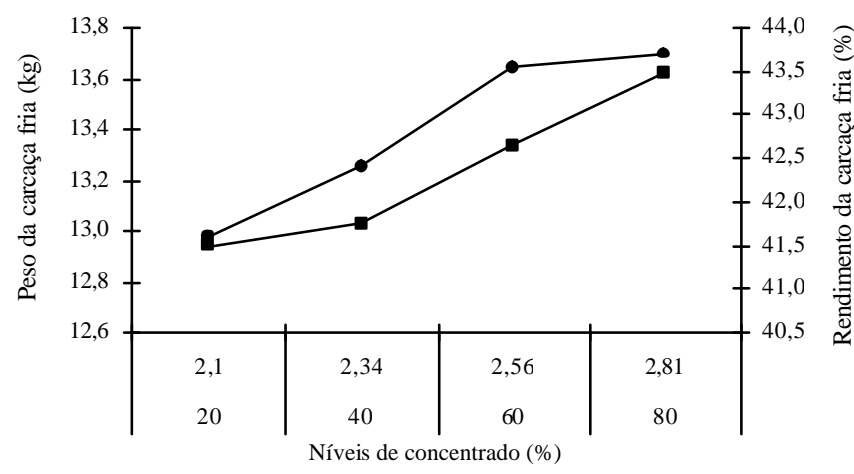

Figura 1 - Peso ( $)$ e rendimento (๑) de carcaça fria de cordeiros Morada Nova terminados em confinamento com diversos níveis de concentrado na dieta. 
de forma quadrática pelos níveis de concentrado da dieta (Tabela 3).

O peso do pescoço em relação ao da carcaça foi de 0,$629 ; 0,653 ; 0,699$ e $0,743 \mathrm{~kg}$. O costilhar apresentou valores de 1,$17 ; 1,16 ; 1,14$ e 1,30 kg para os respectivos níveis de concentrado utilizados nas dietas dos animais, com o ponto de mínima de $41,54 \%$ de concentrado e $1,13 \mathrm{~kg}$ de peso do costilhar. As médias dos pesos das demais regiões anatômicas foram de $1,18 \mathrm{~kg}$ para a paleta; o serrote evidenciou média de $0,856 \mathrm{~kg}$; 0,639 kg para o lombo e 2,06 kg obtido para a perna. A perna foi o corte mais pesado e com o melhor rendimento percentual, pois possui maior musculosidade e maior rendimento da parte comestível (Silva Sobrinho, 2001).

Analisando todas as variáveis, observaram-se diferenças numéricas mínimas entre os pesos dos cortes para cada nível de concentrado (Tabela 3), o que sugere constância desses valores. Essa similaridade de pesos reforça a lei da harmonia anatômica (Boccard \& Dumont, 1960), citada por Siqueira et al. (2001) e Osório et al. (2002a), de que, em carcaças com pesos e quantidades de gordura similares, quase todas as regiões corporais encontram-se em proporções semelhantes, qualquer que seja a conformação do genótipo considerado.

Gonzaga Neto et al. (2006) relataram pesos de 0,60;0,81 e 1,06 kg para a paleta; 1,$05 ; 1,40$ e $1,75 \mathrm{~kg}$ (perna); 0,$33 ; 0,50$ e $0,67 \mathrm{~kg}$ (lombo); 0,$75 ; 1,04$ e $1,33 \mathrm{~kg}$ (costelas) e 0,31; 0,41e 0,51 kg para o pescoço de ovinos Morada Nova alimentados com dietas contendo $30 ; 45$ e $60 \%$ de concentrado, respectivamente. Alves et al. (2003) verificaram em ovinos Santa Inês que os pesos da paleta e costela superior apresentaram curva linear crescente como o aumento dos níveis de energia na dieta.

O rendimento de paleta (Tabela 3 ) representou em torno de 18,$30 ; 18,38 ; 17,62$ e $17,11 \%$; enquanto o de pescoço, 9,$71 ; 10,03 ; 10,48$ e $10,90 \%$. Os rendimentos de perna foram de 31,$40 ; 31,37 ; 31,04$ e 30,70\% para os níveis de 20; 40; 60 e $80 \%$ de concentrado na dieta, respectivamente. Os cortes costilhar, serrote e lombo representaram médias de 18,04; 12,94 e $9,66 \%$, respectivamente.

Ressalta-se que os menores rendimentos da paleta e da perna dos animais alimentados com $80 \%$ de concentrado, os quais demonstraram maiores pesos de carcaça fria, são decorrentes do processo de desenvolvimento precoce destas partes, o que sugere crescimento heterogônico negativo, corroborando informação de Osório et al. (2002a) de que, com aumento do peso da carcaça, a proporção das partes distais reduz-se e a região do tronco permanece praticamente constante, ou seja, o crescimento é centrípeto, inicia nas extremidades e segue em direção ao eixo lombar (Lawrence \& Fowler, 2002), refletindo aumento da compacidade da carcaça.

Considerando os pesos dos cortes e sua valorização comercial, a soma dos cortes considerados de primeira

Tabela 3 - Pesos da meia-carcaça e dos cortes comerciais da carcaça de cordeiros Morada Nova terminados em confinamento com dietas com diversos níveis de concentrado

\begin{tabular}{|c|c|c|c|c|c|c|c|}
\hline \multirow[t]{2}{*}{ Variável } & \multicolumn{4}{|c|}{ Nível de concentrado $(\%)$} & \multirow[t]{2}{*}{$\mathrm{CV}(\%)$} & \multirow[t]{2}{*}{ Equação de regressão } & \multirow[t]{2}{*}{$\mathrm{r}^{2}$} \\
\hline & 20 & 40 & 60 & 80 & & & \\
\hline Peso da meia-carcaça fria, $\mathrm{kg}$ & 6,47 & 6,51 & 6,66 & 6,81 & 5,24 & $\hat{\mathrm{Y}}=6,32386+0,00580828 * \mathrm{C}^{1}$ & 0,95 \\
\hline Paleta, kg & 1,18 & 1,19 & 1,17 & 1,16 & 5,94 & $\hat{\mathrm{Y}}=1,18^{\mathrm{ns}}$ & \\
\hline Pescoço, kg & 0,629 & 0,653 & 0,699 & 0,743 & 11,21 & $\hat{\mathrm{Y}}=0,584281+0,00193797 * \mathrm{C}$ & 0,98 \\
\hline Costilhar, $\mathrm{kg}$ & 1,17 & 1,16 & 1,14 & 1,30 & 9,19 & \multicolumn{2}{|l|}{$\hat{\mathrm{Y}}=1,31409-0,00863430 \mathrm{C}+0,000103926 * \mathrm{C}^{2}$} \\
\hline Serrote, $\mathrm{kg}$ & 0,829 & 0,835 & 0,856 & 0,904 & 10,02 & $\hat{\mathrm{Y}}=0,856^{\mathrm{ns}}$ & \\
\hline Lombo, $\mathrm{kg}$ & 0,626 & 0,620 & 0,661 & 0,651 & 13,32 & $\hat{\mathrm{Y}}=0,639 \mathrm{~ns}$ & \\
\hline Perna, kg & 2,03 & 2,04 & 2,06 & 2,09 & 5,55 & $\hat{\mathrm{Y}}=2,05 \mathrm{~ns}$ & \\
\hline \multicolumn{8}{|c|}{ Rendimento dos cortes, $\%$} \\
\hline Paleta, \% & 18,31 & 18,38 & 17,62 & 17,11 & 4,71 & $\hat{\mathrm{Y}}=18,9416-0,0217890 * \mathrm{C}$ & 0,87 \\
\hline Pescoço, \% & 9,71 & 10,03 & 10,48 & 10,90 & 9,44 & $\hat{\mathrm{Y}}=9,27030+0,0202392 * \mathrm{C}$ & 0,98 \\
\hline Costilhar, \% & 18,13 & 17,87 & 17,12 & 19,06 & 7,32 & $\hat{\mathrm{Y}}=18,04^{\mathrm{ns}}$ & \\
\hline Serrote, $\%$ & 12,85 & 12,82 & 12,84 & 13,26 & 8,45 & $\hat{\mathrm{Y}}=12,94 \mathrm{~ns}$ & \\
\hline Lombo, \% & 9,61 & 9,53 & 9,93 & 9,58 & 11,68 & $\hat{\mathrm{Y}}=9,66^{\mathrm{ns}}$ & \\
\hline Perna, \% & 31,40 & 31,37 & 31,04 & 30,70 & 2,61 & $\hat{\mathrm{Y}}=32,0418-0,0166256 * \mathrm{C}$ & 0,82 \\
\hline
\end{tabular}

${ }^{1}$ Nível de concentrado; $*$ Significativo a $5 \%$ de probabilidade pelo teste $\mathrm{t}$; ns - não-significativo. 
Tabela 4 - Medidas corporais in vivo de ovinos Morada Nova terminados em confinamento com diversos níveis de concentrado na dieta

\begin{tabular}{lccccccc}
\hline Medida corporal in vivo & \multicolumn{3}{c}{ Nível de concentrado $(\%)$} & & CV (\%) & Equação de regressão \\
\cline { 2 - 5 } & 20 & 40 & 60 & 80 & & $\mathrm{r}^{2}$ \\
\hline Comprimento corporal,cm & 57,68 & 56,81 & 56,68 & 57,94 & & 4,58 & $\hat{\mathrm{Y}}=57,28 \mathrm{~ns}$ \\
Perímetro do toráx, cm & 74,75 & 74,75 & 74,62 & 74,94 & & 1,88 & $\hat{\mathrm{Y}}=74,76^{\mathrm{ns}}$ \\
Perímetro da perna, cm & 32,06 & 30,43 & 29,68 & 29,37 & 7,96 & $\hat{\mathrm{Y}}=32,5938-0,0440625^{*} \mathrm{C}^{1}$ & 0,90 \\
Comprimento da perna, cm & 33,75 & 33,94 & 33,00 & 33,56 & 3,13 & $\hat{\mathrm{Y}}=33,56^{\mathrm{ns}}$ \\
Largura da garupa, cm & 14,72 & 14,94 & 14,52 & 14,60 & 3,1 & $\hat{\mathrm{Y}}=14,69 \mathrm{~ns}$ \\
Condição corporal, $(1-5)$ & 3,21 & 3,16 & 3,21 & 3,17 & 9,12 & $\hat{\mathrm{Y}}=3,19 \mathrm{~ns}$ \\
\hline
\end{tabular}

${ }^{1}$ Nível de concentrado; * Significativo a $5 \%$ de probabilidade pelo teste t; ns - não-significativo.

(pernil + lombo) foi de 2,656e 2,66;2,791 e 2,691 kg (Tabela 3) e representa 41,$05 ; 40,86 ; 41,90$ e $39,51 \%$. Para os cortes de segunda, como costilhar + paleta, os valores foram 2,35 ; 2,$35 ; 2,31$ e $2,46 \mathrm{~kg}(36,32 ; 36,09 ; 34,68$ e $36,12 \%)$ e, para os cortes de terceira (pescoço + serrote), os pesos foram de 1,$458 ; 1,488 ; 1,555$ e $1,647 \mathrm{~kg}$, com rendimentos de 22,53; 22,$85 ; 23,35$ e $24,18 \%$, para os ovinos alimentados com 20; 40; 60 e $80 \%$ de concentrado, respectivamente.

Zapata et al. (2001) citam para ovinos Morada Nova da variedade branca, valores de 32,2 a $32,7 \%$ para o pernil; 19,9 a 21,4\% (paleta) e 10,3 a 11,1\% (lombo), em relação à carcaça fria. Neste estudo, os rendimentos foram similares para os mesmos cortes.

O perímetro da perna diminui com o nível de concentrado, apresentando valores de 32,06; 30,43; 29,68 e 29,37 cm, enquanto o comprimento corporal, o perímetro do tórax, o comprimento da perna, a largura da garupa e a condição corporal não foram influenciados $(\mathrm{P}>0,05)$ pelos planos nutricionais utilizados, cujas médias foram de $57,28 \mathrm{~cm}$; $74,76 \mathrm{~cm} ; 33,56 \mathrm{~cm} ; 14,69 \mathrm{~cm}$ e 3,19 , respectivamente (Tabela 4).

É possível que a deposição de músculos e, principalmente, de tecido adiposo na perna não tenha ocorrido em tempo suficiente para o perímetro da perna atingir maiores valores, pois os animais foram abatidos aos 75,25 e 52,5 dias após a entrada no confinamento, quando receberam dietas com 60 e $80 \%$ de concentrado, respectivamente.

De acordo com Bergen (1974), o processo de deposição de proteína e gordura ocorre simultaneamente durante a fase inicial do crescimento do animal, enquanto, no estágio final do desenvolvimento, a deposição de proteína (crescimento muscular) cessa, a do tecido adiposo continua com a idade e o peso corporal.

Os valores do comprimento corporal $(57,28 \mathrm{~cm})$, do perímetro torácico $(74,76 \mathrm{~cm})$, do comprimento da perna $(33,56 \mathrm{~cm})$, da largura da garupa $(14,69 \mathrm{~cm})$ e do escore da condição corporal $(3,19)$ sugerem mensurações de animais compactos (Tabela 4), com valores muito próximos aos encontrados por outros autores quando estudaram genótipos de maior potencial para produção de carne, como Osório et al. (2002b), que relataram valores de 58,8 e 56,4 cm para comprimento corporal; 75,8 e 74,6 para perímetro torácico e escore de 2,7 para a condição corporal in vivo, em cordeiros mestiços Border $\times$ Corriedale e Border $\times$ Ideal, abatidos aos 32,98 e 33,26 kg, respectivamente.

A avaliação da condição corporal é um método subjetivo que permite observar o estado nutricional do animal, mediante a palpação da coluna vertebral logo após a última costela acima da região dos rins. Neste trabalho, o valor médio da nota de condição corporal foi igual a 3,19 e está relacionado a fatores como o peso ao abate, o estado de acabamento, o grau de desenvolvimento e o plano nutricional.

Entre as medidas corporais, o perímetro da perna correlacionou-se de forma positiva $(\mathrm{P}<0,05)$, de $0,380 \mathrm{e}$ 0,405, com a largura da garupa e a condição corporal, respectivamente. As demais mensurações in vivo não foram significativas $(\mathrm{P}>0,05)$ e apresentaram baixas correlações com a condição corporal, que variaram de - 0,25 a 0,184 .

A largura do tórax e a compacidade da carcaça foram lineares crescentes $(\mathrm{P}<0,05)$, com médias de 17,11; 18,01; 19,17 e 23,70 cm e 0,227; 0,232; 0,237 e 0,242 kg/cm, enquanto a largura da garupa mostrou efeito quadrático $(\mathrm{P}<0,05)$, com valores de 13,87; 14,35; 14,66 e 13,52 cm para 20,40, 60 e $80 \%$ de concentrado, respectivamente (Tabela 5). Para as demais medidas, não houve efeito $(\mathrm{P}>0,05)$ dos níveis de concentrado.

A largura do tórax apresentou variação de 17,11 a $23,70 \mathrm{~cm}$. Ressalta-se que a velocidade de crescimento para atingir o peso de abate em menor tempo de confinamento, como nos animais recebendo 60 e $80 \%$ de concentrado, além do aporte de nutrientes fornecidos por estas dietas, exigem do animal estrutura torácica mais larga e profunda para acomodar os órgãos do sistema respiratório e circulatório para que ambos, juntamente com o sistema diges- 
tivo, proporcionem maior circulação de nutrientes pela corrente sangüínea durante a partição desses nutrientes para a deposição dos tecidos muscular e adiposo, refletindo na conformação da carcaça.

A largura da garupa apresentou baixos valores, que variaram de 13,52 a 14,66 cm, com um ponto de máxima $14,61 \mathrm{~cm}$ para o nível de 48,20\% de concentrado, enquanto o perímetro dessa região apresentou média de $54,97 \mathrm{~cm}$. Siqueira et al. (2001) encontraram valores de 14,36; 14,34; 16,06 e $16,50 \mathrm{~cm}$ para largura da garupa de ovinos Ile de France $\times$ Corriedale abatidos aos 28; 32; 36 e 40 kg, respectivamente. As medidas de largura da garupa e do comprimento da perna e a relação (largura/comprimento) são importantes para estimar o grau de conformação dessa região anatômica, pois, quanto maior esta relação, melhor a conformação ou compacidade da perna. Neste estudo, os valores obtidos para a relação largura da garupa/comprimento da perna foram de 0,$416 ; 0,428 ; 0,449$ e 0,407 , para 20 ; 40; 60 e $80 \%$ de concentrados, respectivamente, e foram maiores no nível de $60 \%$ de concentrado.

A cada unidade percentual de concentrado, houve acréscimo de aproximadamente $0,000262 \mathrm{~kg}$ no valor da compacidade da carcaça (Tabela 5). Isto ocorre porque, conforme aumenta em peso, a carcaça se torna relativamente curta, larga e compacta, fato confirmado por Oliveira et al. (1998), que relataram coeficiente de correlação de 0,98 entre a compacidade da carcaça e o peso da carcaça fria.

Alves et al. (2003) não verificaram efeito $(P>0,05)$ do nível de energia metabolizável da dieta sobre os índices de compacidade da carcaça, espessura de gordura e área de olho-de-lombo de ovinos Santa Inês. Osório et al. (2002b) verificaram índices de compacidade da carcaça de 0,258 e $0,246 \mathrm{~kg} / \mathrm{cm}$, para ovinos Border Leicester $\times$ Ideal e Border $\times$ Corriedale, respectivamente.

O resultado da avaliação do grau de conformação da carcaça não apresentou diferença significativa $(\mathrm{P}>0,05)$ e a média da nota foi igual a 3,12. Essa nota é considerada satisfatória, uma vez que os animais da raça Morada Nova foram submetidos menos intensamente a programas de seleção e melhoramento genético para produção de carne.

Por outro lado, o grau de conformação da carcaça apresentou correlação positiva $(\mathrm{P}<0,05)$ com a condição corporal dos ovinos $(0,426)$ e a espessura de gordura da carcaça $(0,338)$.

Siqueira et al. (2001) encontraram graus de conformação de 2,69; 3,00; 2,80 e 2,80 para cordeiros Ile de France $\times$ Corriedale abatidos aos $28,32,36$ e $40 \mathrm{~kg}$, respectivamente. Macedo et al. (2000) verificaram que os cordeiros Corriedale, Corriedale $\times$ Bergamácia e Hampshire Down $\times$ Corriedale confinados apresentaram melhor conformação da carcaça $(3,35)$ em comparação aos terminados na pastagem $(2,65)$. Para cordeiros Border Leicester $\times$ Ideal e Border $\times$ Corriedale, Osório et al. (2002b) relataram valores de 2,3 e 2,5, respectivamente.

A área de olho-de-lombo (AOL) apresentou média de $11,24 \mathrm{~cm}^{2}$ e não foi influenciada pelos níveis de concentrado $(P>0,05)$, mas demonstrou correlação $(\mathrm{P}<0,05)$ com a compacidade da carcaça $(0,326)$.

Gonzaga Neto et al. (2006) encontraram efeito linear crescente para a área de olho-de-lombo e relataram valor

Tabela 5 - Mensurações na carcaça de ovinos Morada Nova terminados em confinamento com diversos níveis de concentrado na dieta

\begin{tabular}{|c|c|c|c|c|c|c|c|}
\hline \multirow[t]{2}{*}{ Variável } & \multicolumn{4}{|c|}{ Nível de concentrado (\%) } & \multirow[t]{2}{*}{$\mathrm{CV}(\%)$} & \multirow[t]{2}{*}{ Equação de regressão } & \multirow[t]{2}{*}{$r^{2}$} \\
\hline & 20 & 40 & 60 & 80 & & & \\
\hline Comprim. interno da carcaça, $\mathrm{cm}$ & 56,71 & 56,65 & 55,92 & 56,14 & 2,88 & $\hat{\mathrm{Y}}=56,36 \mathrm{~ns}$ & \\
\hline Comprimento da perna, $\mathrm{cm}$ & 33,34 & 33,53 & 32,60 & 33,16 & 3,13 & $\hat{\mathrm{Y}}=33,16^{\mathrm{ns}}$ & \\
\hline Perímetro da perna, $\mathrm{cm}$ & 30,27 & 29,06 & 28,85 & 28,87 & 5,76 & $\hat{\mathrm{Y}}=29,26^{\mathrm{ns}}$ & \\
\hline Perímetro do toráx, $\mathrm{cm}$ & 66,20 & 66,50 & 66,12 & 66,94 & 1,46 & $\hat{\mathrm{Y}}=66,44 \mathrm{~ns}$ & \\
\hline Profundidade do tórax, $\mathrm{cm}$ & 24,46 & 24,52 & 25,04 & 24,82 & 4,83 & $\hat{\mathrm{Y}}=24,71 \mathrm{~ns}$ & \\
\hline Largura do tórax, $\mathrm{cm}$ & 17,11 & 18,01 & 19,17 & 23,70 & 12,10 & $\hat{Y}=14,27+0,104606 * C^{1}$ & 0,85 \\
\hline Largura da garupa, $\mathrm{cm}$ & 13,87 & 14,35 & 14,66 & 13,52 & 4,52 & $\hat{Y}=12,2634+0,0973844 * C-0,0010101 C^{2}$ & 0,89 \\
\hline Perímetro da grarupa, $\mathrm{cm}$ & 54,87 & 54,25 & 56,37 & 54,68 & 2,84 & $\hat{\mathrm{Y}}=54,97 \mathrm{~ns}$ & \\
\hline Grau de Conformação, $(1-5)$ & 3,17 & 3,22 & 3,06 & 3,05 & 9,45 & $\hat{\mathrm{Y}}=3,12 \mathrm{~ns}$ & \\
\hline Área de olho de lombo, $\mathrm{cm}^{2}$ & 11,35 & 10,81 & 10,91 & 11,88 & 14,66 & $\hat{\mathrm{Y}}=11,24 \mathrm{~ns}$ & \\
\hline Espessura de gordura, $\mathrm{mm}$ & 1,88 & 1,91 & 1,82 & 1,73 & 23,67 & $\hat{\mathrm{Y}}=1,83^{\mathrm{ns}}$ & \\
\hline Compacidade da carcaça, $\mathrm{kg} / \mathrm{cm}$ & 0,227 & 0,232 & 0,237 & 0,242 & 5,51 & $\hat{\mathrm{Y}}=0,221769+0,000262322 * \mathrm{C}$ & 0,95 \\
\hline
\end{tabular}

${ }^{1}$ Nível de concentrado.

* Significativo a $5 \%$ de probabilidade pelo teste $\mathrm{t}$.

ns - não-significativo. 
de $7,89 \mathrm{~cm}^{2}$ para os ovinos Morada Nova alimentados com $60 \%$ de concentrado na dieta.

A espessura de gordura apresentou valor médio de $1,83 \mathrm{~mm}$ e está associada a fatores como a raça dos animais, o sexo, o plano nutricional e o peso da carcaça. A gordura de cobertura interfere no valor comercial da carcaça, pois é o componente de maior variabilidade e pode ser um fator depreciativo na carcaça, quando em excesso. Entretanto, uma cobertura mínima de gordura é desejável para proteção da carcaça e da carne quanto à perda de água e queimaduras originadas durante os processos de resfriamento e congelamento.

O valor obtido neste estudo é considerado baixo em relação aos encontrados para animais de raças especializadas. No entanto, considerando a atual preferência dos consumidores por carne magra ou com pouca gordura, esse valor pode ser considerado satisfatório.

Ressalta-se que, no momento da evisceração e avaliação da carcaça fria, foram observados maiores depósitos de gordura no omento, mesentério e nas regiões pélvica e renal, com média total de 2,12 kg. Segundo Ermias et al. (2002), essas deposições são decorrentes de efeitos genéticos e ambientais em ovinos tropicais, principalmente como reserva energética, quando há disponibilidade quali e quantitativa de forragens, para mobilização durante o período de escassez.

\section{Conclusões}

O uso de concentrado na dieta eleva os pesos e rendimentos de carcaça fria, mas o aumento nos níveis de concentrado não eleva os pesos e os rendimentos dos cortes da carcaça de ovinos Morada Nova. As medidas corporais não possibilitam estimar a condição corporal de ovinos Morada Nova em confinamento. A raça Morada Nova tem potencial para produção de carne em confinamento.

\section{Agradecimentos}

Ao Conselho Nacional de Pesquisa e Desenvolvimento (CNPq), pela concessão da bolsa de Doutorado.

\section{Literatura Citada}

AGRICULTURAL AND FOOD RESEARCH COUNCIL - AFRC. Energy and protein requirements of ruminants. Wallingford: CAB Internantional, 1993. 159p.

ALVES, K.S.; CARVALHO, F.F.R.; FERREIRA, M.A. et al. Níveis de energia em dietas para ovinos Santa Inês: características de carcaça e constituintes corporais. Revista Brasileira de Zootecnia, v.32, n.6, p.1927-1936, 2003 (supl. 2).
BERGEN, W.G. Protein synthesis in animal models. Journal of Animal Science, v.38, n.5, p.1079-1091, 1974.

COLOMER-ROCHER, F.; MORAND-FEHR, P.; KIRTON, A.H. et al. Métodos normalizados para el estúdio de los caracteres cuantitativos y cualitativos de las canales caprinas y ovinas. Madrid: Ministério da Agricultura, Pesca y Alimentación, 1988. 41p. (Instituto Nacional de Investigaciones Agrárias, Cuadernos 17).

ERMIAS, E.; YAMI, A.; REGE, J.E.O. Fat deposition in tropical sheep as adaptive attribute to periodic feed flutuaction. Journal of Animal Breeding and Genetics, v, 119, p.235-246, 2002.

FERREIRA, M.A.; VALADARES FILHO, S.C.; COELHO DA SILVA, J.F. et al. Eficiência de utilização da energia metabolizável para ganho de peso e exigências de energia metabolizável e nutrientes digestíveis totais de bovinos F1 Simental x Nelore. Revista Brasileira de Zootecnia, v.28, n.2, p.368-373,1998.

FIGUEIREDO, E.A.P.; SIMPLÍCIO, A.A.; RIERA, G.S. et al. Preliminary studies on the carcass characteristics. Pesquisa Agropecuária Brasileira, v.17, n.6, p.951-960, 1982.

FURUSHO-GARCIA, I.F.F.; PEREZ, J.R.O.; BONAGURIO, S. et al. Desempenho de Cordeiros Santa Inês e cruzas Santa Inês com Texel, Ile de France e Bergamácia. In: REUNIÃO DA SOCIEDADE BRASILEIRA DE ZOOTECNIA, 38., 2001, Piracicaba. Anais... Piracicaba: Sociedade Brasileira de Zootecnia, 2001. p.1144-1146

GARRET, W.N. Factors influencing energetic efficiency of beef production. Journal of Animal Science, v.51, n.6, p.1434-1440, 1980.

GONZAGA NETO, S.; SILVA SOBRINHO, A.G.; LOPES, N.M.B. et al. Características quantitativas da carcaça de cordeiros deslanados Morada Nova em função da relação volumoso: concentrado na dieta. Revista Brasileira de Zootecnia, v. 35, n.4, p.1487-1495, 2006.

HADDAD, S.G.; HUSEIN, M.Q. Effect of dietary energy density on growth performance and slaughtering characteristics of fattening Awassi lambs. Livestock Production Science, v.87, p.171-177, 2004

HALL, M.B.; HOOVER, W.H.; JENNINGS, J.P. et al. A method for partitioning neutral detergent soluble carbohydrates. Journal of Science Food Agriculture, v.79, p.2079-2086, 1999.

LAWRENCE, T.L.J.; FOWLER, V.R. Growth in farm animals. 2.ed. Wallingford: CAB International, 2002. 346p.

LAWRIE, R.A. Ciência da carne. Trad. Jane Maria Rubensam. 6.ed. Porto Alegre: Artmed, 2005. 384p.

MACEDO, F.A.F.; SIQUEIRA, E.R.; MARTINS, E.N. et al. Qualidade de carcaças de cordeiros Corriedale, Bergamácia $\mathrm{x}$ Corriedale e Hampshire Down x Corriedale, terminados em pastagem e confinamento. Revista Brasileira de Zootecnia, v. 29, n. 5, p. $1520-1527,2000$.

MAHGOUB, O.; LU, C.D.; EARLY, R.J. Effects of dietary energy density on feed intake, body weight gain and carcass chemical composition of Omani growing lambs. Small Ruminant Research, v.37, p.35-42, 2000.

MÜLLER, L. Normas para avaliação de carcaças e concurso de carcaças de novilhos. Santa Maria: Universidade Federal de Santa Maria, 1980. 31p. (Publicação, 1).

NÄSHOLM, A. Direct and maternal genetic relationships of lamb live weight and carcass traits in Swedish sheep breeds. Journal of Animal Breeding Genetics, v.21, p.66-75, 2004.

NATIONAL RESEARCH COUNCIL - NRC. Nutrient requeriments of sheep. 6.ed. Washington, D.C.: National Academy Press. 1985. 99p.

OLIVEIRA, N.M.; OSÓRIO, J.C.S.; SELAIVE-VILLARROEL, A. et al. Produção de carne em ovinos de cinco genótipos. 5. Estimativas de qualidade e peso de carcaça através do peso vivo. Ciência Rural, v.28, n.4, p.665-669, 1998.

OSÓRIO, J.C.S.; OSÓRIO, M.T.M.; OLIVEIRA, N.M. et al. Qualidade, morfologia e avaliação de carcaças. Pelotas: Universidade Federal de Pelotas, 2002a. 194p. 
OSÓRIO, J.C.S.; OLIVEIRA, N.M.; OSÓRIO, M.T.M. et al. Produção de carne em cordeiros cruza Border Leicester com ovelhas Corriedale e Ideal. Revista Brasileira de Zootecnia, v.31, n.3, p.1469-1480, 2002b (supl.).

PURCHAS, R.W.; SILVA SOBRINHO, A.G.; GARRICK, D.J. et al. Effects of age at salughter and sire genotype on fatness, muscularity, and the quality of meat from ram lambs born to Romney ewes. New Zealand Journal of Agricultural Research, v.45, p.77-86, 2002.

REID, J.T.; WHITE, O.D.; ANRIQUE, R. et al. Nutritional energetics of livestock: some present boundaries of knowledge and future research needs. Journal of Animal Science, v.51, n.6, p.1393-1415, 1980.

SAÑUDO, C. Factors affecting carcass and meat quality in lambs. In: REUNIÃO ANUAL DA SOCIEDADE BRASILEIRA DE ZOOTECNIA, 39., 2002, Recife. Palestras... Recife: Sociedade Brasileira de Zootecnia, 2002. p.435-455.

SILVA SOBRINHO, A.G. Aspectos quantitativos e qualitativos da produção de carne ovina. In: REUNIÃO ANUAL DA SOCIEDADE BRASILEIRA DE ZOOTECNIA, 38., 2001, Piracicaba. Palestras... Piracicaba: Sociedade Brasileira de Zootecnia, 2001. p.425-446.

SNIFFEN, C.J.; O'CONNOR, J.D.; Van SOEST, P.J. et al. A net carbohidrate and protein system for evaluating cattle diets: II. Carbohydrate and protein availability. Journal of Animal Science, v.70, p.3562-3577, 1992.

SIQUEIRA, E.R.; SIMÕES, C.D.; FERNANDES, S. Efeito do sexo e do peso ao abate sobre a produção de carne de cordeiro. Morfologia da carcaça, peso dos cortes, composição tecidual e componentes não constituintes da carcaça. Revista Brasileira de Zootecnia, v.30, n.4, 1299-1307, 2001.

UNIVERSIDADE FEDERAL DE VIÇOSA - UFV. Sistema de análises estatísticas e genéticas - SAEG. Viçosa, MG: UFV, 2001. 301p.

SNOWDER, G.D.; GLIMP, H.A.; FIELD, R.A. Carcass characteristics and optimal slaughter weights in four breeds of sheep. Journal of Animal Science, v.72, p.932-937, 1994.

SUSIN, I. Confinamento de cordeiros. In: REUNIÃO ANUAL DA SOCIEDADE BRASILEIRA DE ZOOTECNIA, 38., 2001, Piracicaba. Palestras... Piracicaba: Sociedade Brasileira de Zootecnia, 2001. p.454-459.

SUSIN, I. Exigências nutricionais de ovinos e estratégias de alimentação. In: SILVA SOBRINHO, A.G.; BATISTA, A.M.V.; SIQUEIRA, E.R. et al. (Eds.) Nutrição de ovinos. Jaboticabal: FUNEP, 1996. p.119-141.

TRALDI, A.S. Performance reprodutiva dos ovinos deslanados no Brasil. In: PRODUÇÃO DE OVINOS: CURSO DE EXTENSÃO UNIVERSITÁRIA EM PRODUÇÃO DE OVINOS, 1990, Jaboticabal. Anais... Jaboticabal: FUNEP, 1990. p.81-124.

VASCONCELOS, V.R.; BARROS, N.N. Nutrição de caprinos e ovinos jovens..In: CONGRESSO NORDESTINO DE PRODUÇÃO ANIMAL, 2., 2000, Teresina. Anais... Teresina: Sociedade Nordestina de Produção Animal, 2000. p.143-153.

ZAPATA, J.FF.; SEABRA, L.M.A.J.; NOGUEIRA, C.M. et al. Características de carcaça de pequenos ruminantes do Nordeste do Brasil. Revista Ciência Animal, v.11, n.2, p.79-86, 2001.

WEISS, W.P. Energy prediction equations for ruminant feeds. In: CORNELL NUTRITION CONFERENCE FEED MANUFACTURES, 61., 1999, Ithaca. Proceedings... Ithaca: Cornell University, 1999. p.176-185. 